\title{
Article
}

\section{Tensile Test of Human Lumbar Ligamentum Flavum: Age-Related Changes of Stiffness}

\author{
Atsushi Mihara ${ }^{1}$, Norihiro Nishida ${ }^{1, *}{ }^{\mathbb{C}}$, Fei Jiang ${ }^{2}$, Junji Ohgi ${ }^{2}$, Yasuaki Imajo ${ }^{1}$, Hidenori Suzuki ${ }^{1}{ }^{\mathbb{D}}$, \\ Masahiro Funaba ${ }^{1}$, Hiroki Yamagata ${ }^{1} \mathbb{D}$, Xian Chen $^{2}$ and Takashi Sakai ${ }^{1}$ \\ 1 Department of Orthopedic Surgery, Yamaguchi University Graduate School of Medicine, \\ 1-1-1 Minami-Kogushi, Ube, Yamaguchi 755-8505, Japan; a-miha@yamaguchi-u.ac.jp (A.M.); \\ i-yasuak@yamaguchi-u.ac.jp (Y.I.); hsuzuki@yamaguchi-u.ac.jp (H.S.); funa51.mf@gmail.com (M.F.); \\ hiroki.ymgt@gmail.com (H.Y.); cozy@yamaguchi-u.ac.jp (T.S.) \\ 2 Department of Mechanical Engineering, Yamaguchi University, 2-16-1 Tokiwadai Ube, \\ Yamaguchi 755-8611, Japan; fjiang@yamaguchi-u.ac.jp (F.J.); ohgi@yamaguchi-u.ac.jp (J.O.); \\ xchen@yamaguchi-u.ac.jp (X.C.) \\ * Correspondence: nishida3@yamaguchi-u.ac.jp; Tel.: +81-836-22-2268
}

check for updates

Citation: Mihara, A.; Nishida, N.; Jiang, F.; Ohgi, J.; Imajo, Y.; Suzuki, H.; Funaba, M.; Yamagata, H.; Chen, X.; Sakai, T. Tensile Test of Human Lumbar Ligamentum Flavum: Age-Related Changes of Stiffness. Appl. Sci. 2021, 11, 3337. https:// doi.org/10.3390/app11083337

Academic Editor: Ana Paula Betencourt Martins Amaro

Received: 15 March 2021

Accepted: 6 April 2021

Published: 8 April 2021

Publisher's Note: MDPI stays neutral with regard to jurisdictional claims in published maps and institutional affiliations.

Copyright: (c) 2021 by the authors. Licensee MDPI, Basel, Switzerland. This article is an open access article distributed under the terms and conditions of the Creative Commons Attribution (CC BY) license (https:// creativecommons.org/licenses/by/ $4.0 /)$.

\begin{abstract}
The most common cause of lumbar spinal canal stenosis is age-related degenerative changes. The ligamentum flavum is said to become thicker and stiffer with age, based on several histological and cadaver studies. However, there are no studies determining the age-related changes of the mechanical properties of the ligamentum flavum in live patients. We examined the mechanical properties of the ligamentum flavum of live patients and evaluated the age-related changes. A total of 44 patients undergoing decompression surgery due to lumbar disease at our institute were included. The ligamentum flavum was harvested from the decompression site as a part of a necessary procedure for decompression. The tensile test was performed for the harvested ligamentum flavum within $24 \mathrm{~h}$ of harvest. Age-related changes in the stiffness of the ligamentum flavum were evaluated. Age was the only factor that showed a significant correlation with stiffness on multiple regression analysis. We demonstrated that the mechanical properties of the ligamentum flavum change with age.
\end{abstract}

Keywords: ligamentum flavum; lumbar spinal canal stenosis; mechanical property; tensile test; stiffness

\section{Introduction}

The ligament flavum is a structure that covers the posterior side of the spinal canal. It adheres to the upper and lower lamina, maintains tension in both the resting and moving state, and maintains pressure to strengthen the intervertebral disc. As a result, it adapts and controls the motion of the spine, which protects the spinal cord by buffering action against rapid external force [1,2].

Lumbar spinal canal stenosis (LSS) is a degenerative disease with a predilection for middle-aged and elderly patients [3,4]. Although several factors such as osteophytes, intervertebral disc herniation, degenerative slipping and instability are involved in the development of spinal canal stenosis, changes in the ligamentum flavum associated with aging is one of the most important factors. Ligamentum flavum is thickened and buckled inside the spinal canal as the disc height decreases due to degenerative changes $[5,6]$. Furthermore, hypertrophy of the ligamentum flavum is thought to be most involved in the development of LSS [7].

To date, there have been several reports describing the histological changes in the ligamentum flavum according to age and disease [8-13]. Hypertrophy of the ligamentum flavum seems to be strongly associated in the development of LSS [7]. Few reports have described the biochemical changes that cause the hypertrophy [14,15]. Although it is natural to consider that the mechanical properties of ligamentum flavum can be altered due to ligamentous hypertrophy, only few studies have mentioned on this point $[1,16,17]$. 
In a cadaver ligamentum flavum tensile test experiment, Nachemson et al. reported that values for stress at rupture decreased with age and showed significant age correlation [1]. Tkaczuk also reported in cadaver experiments that the modules of elasticity at rupture decreased significantly with age [16]. Recently, Jezek et al. reported that healthy ligaments were significantly stiffer than LSS ligaments measured by nanoindentation, using fresh ligaments harvested during surgery [17]. However, to date, there are no reports demonstrating tensile tests with fresh human ligamentum flavum and evaluate the factors that affect the mechanical properties. Therefore, in this report, we conducted tensile tests of ligamentum flavum harvested from live patients during decompression surgery, and evaluated the mechanical properties. We focused on the stiffness of the ligaments and evaluated the factors that associated with the change in stiffness.

\section{Materials and Methods}

This study was conducted after approval was obtained from the Ethics Committee of our institute, and written informed consent was received from each patient (H27-009, H28-054). Patients visiting our institute with lumbar disease showing nerve root symptoms or cauda equina symptoms treated with surgery (decompression or decompression-fusion) were included. Exclusion criteria were patients under 20 years of age, patients with infection (syphilis, hepatitis B, hepatitis $C$, acquired immune deficiency syndrome) considering the examiner's safety, patients with ossification of the ligaments, patients undergoing secondary operations, and patients in whom adhesion of the ligament and the dura was strong and en bloc excision of the ligament was impossible. A total of 44 patients ( 23 men, 21 women) with a mean age of 66.5 (range, 33-85) years were included in the study.

The ligamentum flavum was harvested during the operation from the site of decompression as a part of a necessary procedure for decompression. This tissue is normally disposed of. At every surgery, we aimed to completely separate the ligamentum flavum from the dura mater en bloc, including the deep layer.

The harvested ligaments were brought to the department of mechanical engineering of our university wrapped in gauze that had been soaked in $36{ }^{\circ} \mathrm{C}$ saline, and tensile testing was conducted within $24 \mathrm{~h}$ after harvesting. All tests were practiced in the same room with the room temperature at $25{ }^{\circ} \mathrm{C}$. After the test, the samples were brought back to our institute and were disposed of in the general method of infectious waste.

The harvested ligamentum flavum samples were sliced to $1.5 \mathrm{~mm}$ in width, $1.5 \mathrm{~mm}$ in thickness, and $10 \mathrm{~mm}$ in length with a surgical knife. Samples not reaching $10 \mathrm{~mm}$ in length were excluded. A total of 152 sample specimens were obtained. To fix the sample to the tensile testing machine, we made a plastic tab with a 3D-printer (Creator Pro; APPLE TREE Co., Ltd., Osaka, OS, Japan). The samples were glued to the tabs by sandwiching the sample with two tabs with instant glue at both ends (Figure 1). The tabs were fixed to the tab fastener of the tensile testing machine. The gauge distance of the samples was set at $5 \mathrm{~mm}$. Saline $\left(36^{\circ} \mathrm{C}\right)$ was frequently sprayed on the samples in order to keep them wet.

Figure 2 shows the tensile testing machine used in this experiment. The lower and upper tab fasteners, where the samples glued to the tabs were fixed, are attached to the load cell (LTS-1KA; KYOWA Co., Ltd., Tokyo, TY, Japan) and the sliding part, respectively. As the actuator (directly below the sliding part) moves upward, the sliding part to which the upper tab fastener is attached is pushed up, and load is given to the fixed samples monoaxially. The signal measured by the load cell is converted into a voltage by a dynamic strain measuring device (DPY-713B; KYOWA Co., Ltd., Tokyo, TY, Japan) and displayed on the personal computer (PC) via a data logger (PCD-320A; KYOWA Co., Ltd., Tokyo, TY, Japan). An aluminum foil as an electrode was installed on the actuator side of the contact part of the actuator and slide part; this is connected to a power supply device (PR18-3A; TEXIO TECHNOLOGY Co., Ltd., Yokohama, KN, Japan). As a result, a voltage change occurs when the slide part and the actuator come into contact, and by reading with a PC via the data logger, the time at which the slide part starts to move is known and the time at which the tensile load of the sample starts can be measured. 


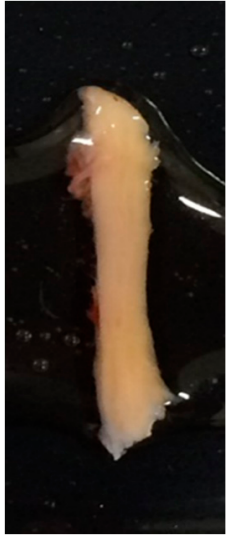

(a)

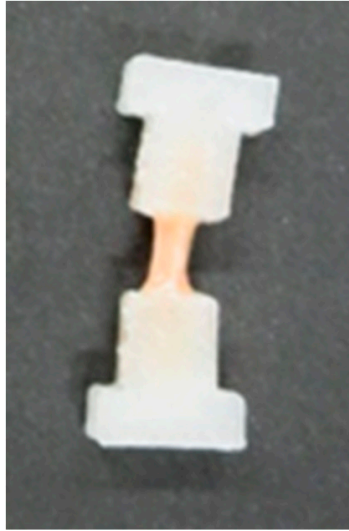

(b)

Figure 1. Pictures of the harvested ligamentum flavum: (a) Samples were sliced to $1.5 \mathrm{~mm}$ in width, $1.5 \mathrm{~mm}$ in thickness, and $10 \mathrm{~mm}$ in length; (b) Plastic tabs made by a 3D printer were glued to both ends of the samples in order to attach the samples to the tensile testing machine.

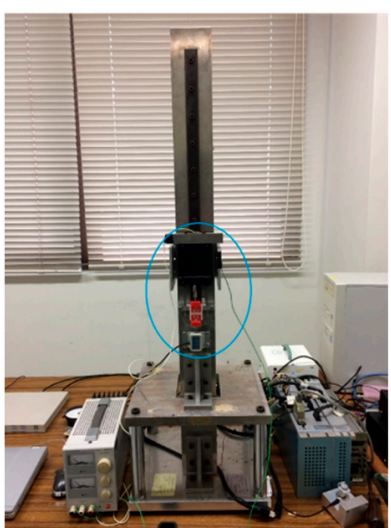

(a)

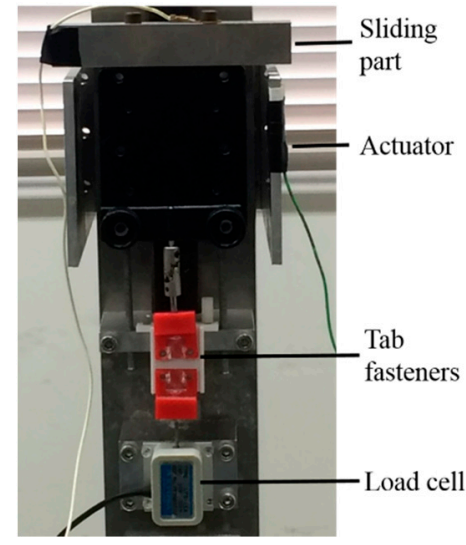

(b)

Figure 2. Pictures of the tensile testing machine used in this study: (a) The entire tensile testing machine; (b) Enlarged view of the testing machine and names of each part.

Tensile rate was set to $0.1 \mathrm{~mm} / \mathrm{s}$ for all tests. The tabs on both ends of the specimen were fixed to the upper and lower tab fasteners without applying any load to the specimen. After that, the distance between the tabs is gradually increased, and the point where the load started to apply was set as the starting point. We confirmed that the distance between the tabs of the sample was $5 \mathrm{~mm}$, the same as the gauge distance of the samples. Further load was applied until fracture of the specimen. The amount of load and stretch of the specimen was measured. Stress $(\sigma)$ and strain $(\varepsilon)$ was calculated from the measured load and stretch. The following is the calculation formula for calculating stress $(\sigma)$. " $\mathrm{A}$ " is the cross-sectional area of the specimen and " $\mathrm{P}$ " is the load measured in the experiment:

$$
(\sigma)=\mathrm{P} / \mathrm{A}[\mathrm{MPa}]
$$

The following is the calculation formula for calculating strain $(\varepsilon)$. $(\delta)$ is the stretch measured in the experiment. $\mathrm{L}$ is the gauge distance of the samples and was set to $5 \mathrm{~mm}$ in all samples:

$$
(\varepsilon)=(\delta) / \mathrm{L}
$$

Stiffness for the elastic region of the specimen was calculated from the slope of the obtained stress $(\sigma)$-strain $(\varepsilon)$ curve, up to the start of specimen fracture. In cases where multiple specimens could be prepared from the collected ligament from one individual, 
all specimens were subjected to the tensile test and the stiffness was calculated. Since the specimens were made from the same individual at the same level in the spine, the average value of the specimens was used as the stiffness value for that individual.

Statistical analysis was performed with StatFlex Ver. 6 (Artech Co., Ltd., Osaka, OS, Japan). We observed the correlation of stiffness of the ligamentum flavum with age, gender and type of disease by multiple regression analysis. The correlation was considered statistically significant at $p$-value $<0.05$.

\section{Results}

The mean stiffness of all samples was $4.358 \pm 1.621 \mathrm{MPa}$. The mean stiffness of male and female samples were $4.266 \pm 1.535 \mathrm{MPa}$ and $4.459 \pm 1.744 \mathrm{MPa}$, respectively ( $t$-test; n.s.). The mean stiffness of LSS and non-LSS samples were $4.644 \pm 1.393 \mathrm{MPa}$ and $3.746 \pm 1.944 \mathrm{MPa}$, respectively ( $t$-test; n.s.). The results of stiffness for all samples are shown in Table 1 . The results of multiple regression analysis with target variable set to stiffness are shown in Table 2. Only age showed a significant correlation $(p=0.0004$, adjusted $R^{2}=0.3094$ ), while gender and type of disease showed no significance. Scatter plots showing the relationship between age and stiffness is shown in Figure 3. The value of stiffness increased with age, whether divided into male, female, LSS, or non-LSS samples.

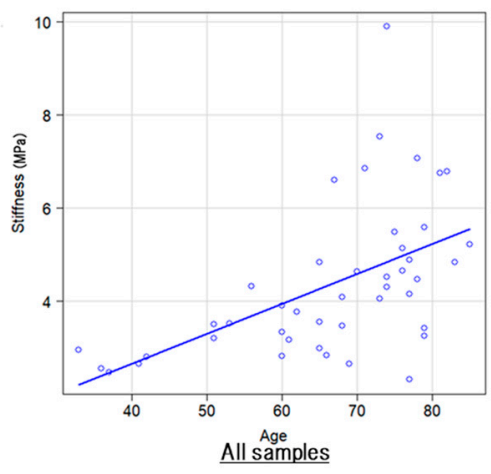

(a)

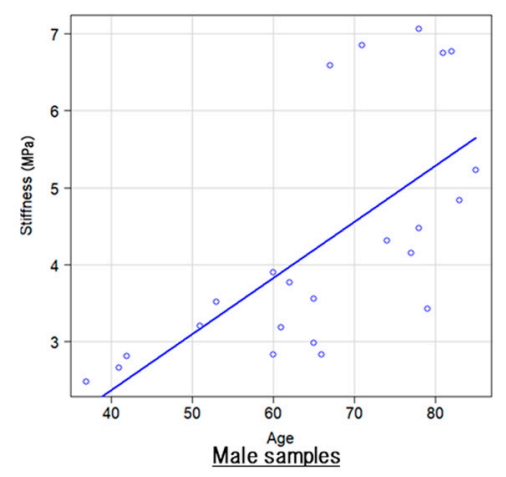

(b)

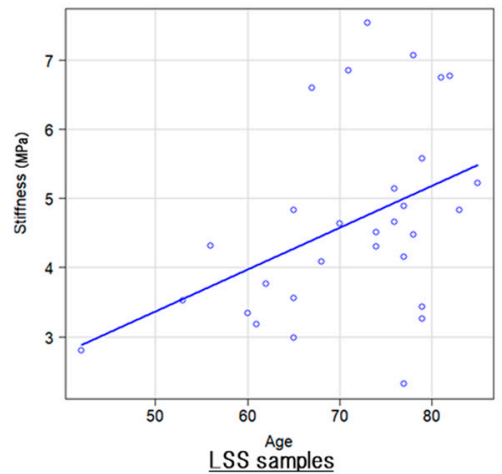

(d)

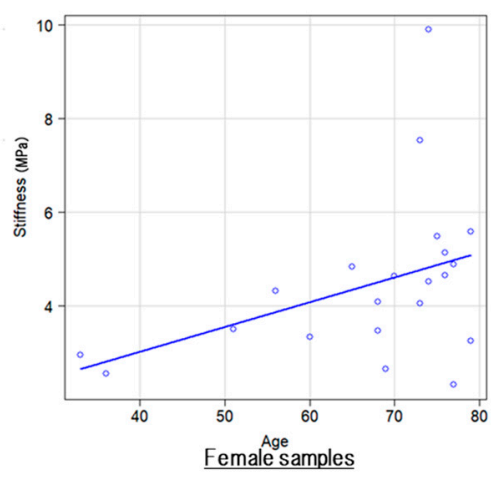

(c)

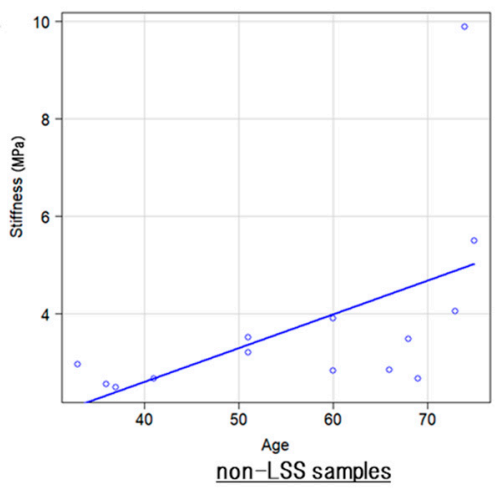

(e)

Figure 3. Scatter plots of the relationship between age and stiffness showed increase in stiffness with age: (a) results of all samples; (b) results of male samples; (c) results of female samples; (d) results of LSS samples; (e) results of non-LSS samples. 
Table 1. Results of stiffness for all samples.

\begin{tabular}{|c|c|c|c|}
\hline Age & Gender $^{1}$ & Disease $^{2}$ & Stiffness Mean \pm STD $(\mathrm{MPa})$ \\
\hline 33 & $\mathrm{~F}$ & Schwannoma & $2.951 \pm 0$ \\
\hline 36 & $\mathrm{~F}$ & $\mathrm{LDH}$ & $2.545 \pm 0$ \\
\hline 37 & M & $\mathrm{LDH}$ & $2.470 \pm 0.917$ \\
\hline 41 & M & LDH & $2.656 \pm 0$ \\
\hline 42 & M & LSS & $2.803 \pm 0.582$ \\
\hline 51 & M & $\mathrm{LDH}$ & $3.198 \pm 0.471$ \\
\hline 51 & $\mathrm{~F}$ & $\mathrm{LDH}$ & $3.501 \pm 0.865$ \\
\hline 53 & M & LSS & $3.518 \pm 0$ \\
\hline 56 & $\mathrm{~F}$ & LSS & $4.310 \pm 0.403$ \\
\hline 60 & M & $\mathrm{LDH}$ & $2.826 \pm 0.172$ \\
\hline 60 & M & $\mathrm{LDH}$ & $3.894 \pm 0.429$ \\
\hline 60 & $\mathrm{~F}$ & LSS & $3.341 \pm 1.150$ \\
\hline 61 & M & LSS & $3.177 \pm 0$ \\
\hline 62 & M & LSS & $3.769 \pm 0.762$ \\
\hline 65 & M & LSS & $2.982 \pm 0.440$ \\
\hline 65 & M & LSS & $3.557 \pm 0$ \\
\hline 65 & $\mathrm{~F}$ & LSS & $4.831 \pm 0.533$ \\
\hline 66 & M & $\mathrm{LDH}$ & $2.832 \pm 0.947$ \\
\hline 67 & M & LSS & $6.592 \pm 0.543$ \\
\hline 68 & $\mathrm{~F}$ & $\mathrm{LDH}$ & $3.475 \pm 0.549$ \\
\hline 68 & $\mathrm{~F}$ & LSS & $4.081 \pm 0$ \\
\hline 69 & $\mathrm{~F}$ & $\mathrm{LDH}$ & $2.662 \pm 0.746$ \\
\hline 70 & $\mathrm{~F}$ & LSS & $4.632 \pm 0.984$ \\
\hline 71 & M & LSS & $6.849 \pm 0$ \\
\hline 73 & $\mathrm{~F}$ & $\mathrm{LDH}$ & $4.047 \pm 0.993$ \\
\hline 73 & $\mathrm{~F}$ & LSS & $7.538 \pm 0.572$ \\
\hline 74 & $\mathrm{~F}$ & $\mathrm{LDH}$ & $9.892 \pm 2.527$ \\
\hline 74 & M & LSS & $4.309 \pm 0.523$ \\
\hline 74 & $\mathrm{~F}$ & LSS & $4.510 \pm 0.386$ \\
\hline 75 & $\mathrm{~F}$ & Schwannoma & $5.490 \pm 0.661$ \\
\hline 76 & $\mathrm{~F}$ & LSS & $4.656 \pm 1.211$ \\
\hline 76 & $\mathrm{~F}$ & LSS & $5.141 \pm 0.025$ \\
\hline 77 & $\mathrm{~F}$ & LSS & $4.889 \pm 1.032$ \\
\hline 77 & M & LSS & $4.150 \pm 0.776$ \\
\hline 77 & $\mathrm{~F}$ & LSS & $2.314 \pm 0.669$ \\
\hline 78 & M & LSS & $4.470 \pm 1.940$ \\
\hline 78 & M & LSS & $7.063 \pm 0$ \\
\hline 79 & $\mathrm{~F}$ & LSS & $3.260 \pm 0.670$ \\
\hline 79 & $\mathrm{~F}$ & LSS & $5.581 \pm 0.852$ \\
\hline 79 & M & LSS & $3.427 \pm 0.754$ \\
\hline 81 & M & LSS & $6.749 \pm 0$ \\
\hline 82 & M & LSS & $6.773 \pm 0$ \\
\hline 83 & M & LSS & $4.832 \pm 1.020$ \\
\hline 85 & M & LSS & $5.223 \pm 0.975$ \\
\hline
\end{tabular}

${ }^{1}$ M: Male; F: Female ${ }^{2}$ LDH: Lumbar disc hernia; LSS: Lumbar spinal canal stenosis.

Table 2. Multiple regression analysis results. Target variable: stiffness.

\begin{tabular}{|c|c|c|}
\hline Variable & $\operatorname{std} \beta$ & $p$-Value \\
\hline Age & 0.5731 & 0.0004 \\
\hline Gender & -0.0374 & n.s. \\
\hline LSS $^{1}$ & 0.1108 & n.s. \\
\hline Non-LSS ${ }^{1}$ & 0.1203 & n.s. \\
\hline
\end{tabular}

${ }^{1}$ LSS: Lumbar spinal canal stenosis. 


\section{Discussion}

Hypertrophy of the ligamentum flavum plays an important role in the onset of LSS [7]. LSS is a degenerative disease more likely to occur in the elderly, and the incidence rate increase with age. Thus, aging seems to correlate with ligamentous hypertrophy. Indeed, Chuang et al. reported the age-related hypertrophy of ligamentum flavum mediated by oxidative stress [18]. Since the mechanical properties of the ligamentum flavum can be thought to change as ligamentous hypertrophy occurs, we hypothesized that the mechanical properties of ligamentum flavum may change with aging also. Although there are several reports in the literature studying anatomical and histological age-related changes of the ligamentum flavum, there are only a small number of studies reporting the relationship between mechanical properties and aging.

In anatomical research, it has been reported that the ligamentum flavum loses its homogenous appearance with age. In elderly patients, small cysts, fat infiltration, and calcification are seen in the ligaments which may lead to thickening and changes in mechanical property [6]. Abbas et al. reported the thickening of the ligamentum flavum is an age-dependent phenomenon [19]. On the other hand, Safak et al. reported that the thickness of the ligamentum flavum does not differ by gender and does not correlate with age [20]. Kim et al. reported that since the thickness of the ligamentum flavum can increase by buckling due to disc height decrease with no histological change, hypertrophy and thickness is somewhat different [21]. Hypertrophy does result in thickening of the ligament; however, thickening of the ligament does not always mean the occurrence of ligamentous hypertrophy.

Histologically, the normal ligamentum flavum consists of approximately $80 \%$ elastic fibers and $20 \%$ collagen fibers [8]. The viscoelasticity of the ligament decreases with advancing degeneration. This is because fibrous tissue formation and subsequent hypertrophy occur in the elastic fibers. Sairyo et al. reported that fibrosis is the main cause of ligamentum flavum hypertrophy, and fibrosis is caused by the accumulation of mechanical stress with the aging process [22]. Furthermore, loss of elastic fibers and increase of calcification in the ligaments leading to loss of elasticity was associated with age $[9,10]$. As the elastic fibers gradually disappear a relative increase of collagen fibers and subsequent fibrosis of the ligament are seen leading to hypertrophic changes [11,13]. Recently, as causes for hypertrophy, angiogenesis following mechanical stress and inflammation promoted by angiopoietin-like protein 2 have been reported [14]. Summarizing the results of anatomical and histological studies, it appears that the hypertrophic change of the ligamentum flavum is associated with age due to the effects of mechanical stress and chronic inflammation.

When we look at the mechanical properties of ligamentum flavum, there are several cadaveric studies measuring the mechanical properties by several methods. These reports revealed the importance of the posterior ligaments in braking performance during flexion, retroflexion, and rotation of the lumbar spine [23-26]. However, there are only a few reports that verify changes in the mechanical properties associated with age $[1,16,17]$. Cadaveric studies demonstrated that the ligamentum flavum loses its elasticity with aging, supporting the histological reports $[1,16]$.

Based on this prior knowledge, we conducted tensile testing of the fresh human ligamentum flavum. As previously reported, the stress $s(\sigma)$-strain $(\varepsilon)$ relationship showed a sigmoidal curve before breakage [23,24]. We calculated the stiffness of the ligamentum flavum from the stress $(\sigma)$-strain $(\varepsilon)$ relationship diagram. Our results show that stiffness of the ligamentum flavum increases with age, regardless of gender or type of disease. As shown in the scatter plots between age and stiffness, stiffness increases at a constant rate, regardless of gender and disease. This result and previous anatomical and histological reports suggest that the ligamentum flavum becomes thick and stiff due to degeneration associated with aging. Since LSS did not associate with stiffness, stiffening of the ligaments may start before or at early stages of hypertrophy and thickening of ligamentum flavum.

Recently, Jezek et al. reported the stiffness of fresh ligamentum flavum in LSS and nonLSS patients measured by nanoindentation. Surprisingly, in their report, healthy ligaments 
were significantly stiffer than LSS ligaments. They also demonstrated that vascularity of the ligament decreases with age leading to degenerative changes. However, evaluation of age-related changes in stiffness was not conducted and stiffness was measured only in two cases with LSS and one case from the control group, which may be the reason for the difference between our results [17].

We have conducted several mechanical property tests in animal experiments and used the data obtained from these tests in computer analysis using the three-dimensional finite elemental method (3D-FEM) of the spine and spinal cord [27,28]. However, in order to conduct a more accurate computer analysis, it was necessary to verify how the mechanical properties of the tissue changes correlate with aging. Okazaki et al. reported age-related changes of fresh bovine spinal cord mechanical properties and showed significant difference between young and old samples [28]. However, such changes in the mechanical properties of living human are not frequently investigated. Experiments with fresh human tissues are very difficult because there are very limited opportunities to harvest tissues from a live human individual. Therefore, in this study, we used ligamentum flavum tissues that were excised for decompression of the spinal canal and verified the age-related changes based on the mechanical properties.

This is the first study to demonstrate age-related changes in the mechanical properties of fresh human tissues from several individuals. This result showed that stiffness of live human tissue show increase with aging, which must be considered in computer analysis using 3D-FEM. The mechanical properties demonstrated in this study will allow us to confirm more accurate and age-related computer analysis using 3D-FEM for pre-operative planning. Further, by developing this study, analyzing the velocity dependence, we can understand the level of force and speed in which ligament tissues will be damaged. These findings may deepen our knowledge of dislocation of the vertebral or ligamentum flavum hematoma in spine injuries. If we analyze our data for mechanical properties along with medical images such as magnetic resonance imaging, we can increase the amount of information that can be obtained from the images. This study can be applied to several areas of research in the biomechanical field of spine surgeons.

There are some limitations to this study. Not only hypertrophy and age-related degeneration of the ligamentum flavum, but also anterior elements such as the intervertebral disc, dynamic factors, arteriovenous stagnation, and degeneration of nerve fibers can lead to the appearance of LSS symptoms. Therefore, the age-related changes of the ligamentum flavum may not directly lead to symptoms of LSS. Moreover, since we used tissues harvested in surgery, and duration of disease was variable, we do not know whether changes would be the same or similar in patients without symptoms. In the study, we did not evaluate the histological findings of the harvested ligaments. Hence, we could not evaluate the association of stiffness and histological hypertrophic changes.

In conclusion, although the samples of the ligamentum flavum were from patients with lumbar disease, we demonstrated that the mechanical properties of human tissue change with age, and we determined the mechanical properties at different ages in this analysis. The mechanical properties demonstrated in this study will allow us to confirm more accurate and age-related computer analysis in biomechanical studies.

Author Contributions: Conceptualization, N.N., F.J., J.O. and X.C.; Data curation, A.M., N.N. and J.O.; Formal analysis, A.M.; Funding acquisition, N.N.; Methodology, N.N., F.J., J.O. and X.C.; Project administration, N.N.; Resources, N.N., Y.I., H.S., M.F. and H.Y.; Supervision, T.S.; Validation, N.N., J.O. and X.C.; Visualization, A.M.; Writing—original draft, A.M.; Writing-review \& editing, N.N. and T.S. All authors have read and agreed to the published version of the manuscript.

Funding: This research was funded by JSPS KAKENHI Grant Numbers JP 15K20002, University School of Medicine affiliated hospital: Translational promotion grant.

Institutional Review Board Statement: The study was conducted according to the guidelines of the Declaration of Helsinki, and approved by the Ethics Committee of Yamaguchi University Graduate School of Medicine (H27-009, H28-054). 
Informed Consent Statement: Informed consent was obtained from all subjects involved in the study.

Data Availability Statement: The data presented in this study are available on request from the corresponding author.

Acknowledgments: The authors express their gratitude for the cooperation provided by the members of the Medical and Mechanical Engineering Laboratory of Yamaguchi University, and graduate students from this laboratory. The authors also express their gratitude for the advice on statistical processing provided by Kiyoshi Ichihara, professor of Faculty of Health Sciences, Department of Clinical Laboratory Sciences, Yamaguchi University Graduate School of Medicine.

Conflicts of Interest: The authors declare no conflict of interest.

\section{References}

1. Nachemson, A.L.; Evans, J.H. Some mechanical properties of the third human lumbar interlaminar ligament (ligamentum flavum). J. Biomech. 1968, 1, 211-220. [CrossRef]

2. Nachemson, A.; Lewin, T.; Maroudas, A.; Freeman, M.A. In vitro diffusion of dye through the end-plates and the annulus fibrosus of human lumbar inter-vertebral discs. Acta Orthop. Scand. 1970, 41, 589-607. [CrossRef] [PubMed]

3. Trigg, S.D.; Devilbiss, Z. Spine Conditions: Lumbar Spinal Stenosis. FP Essent. 2017, 461, 21-25. [PubMed]

4. Lee, J.Y.; Whang, P.G.; Lee, J.Y.; Phillips, F.M.; Patel, A.A. Lumbar spinal stenosis. Instr. Course Lect. 2013, 62, $383-396$.

5. Yabe, Y.; Hagiwara, Y.; Ando, A.; Tsuchiya, M.; Minowa, T.; Takemura, T.; Honda, M.; Hatori, K.; Sonofuchi, K.; Kanazawa, K.; et al. Chondrogenic and fibrotic process in the ligamentum flavum of patients with lumbar spinal canal stenosis. Spine 2015, 40, 429-435. [CrossRef]

6. Poletti, C.E. Central lumbar stenosis caused by ligamentum flavum: Unilateral laminotomy for bilateral ligamentectomy: Preliminary report of two cases. Neurosurgery 1995, 37, 343-347. [CrossRef] [PubMed]

7. Sun, C.; Zhang, H.; Wang, X.; Liu, X. Ligamentum flavum fibrosis and hypertrophy: Molecular pathways, cellular mechanisms, and future directions. FASEB J. 2020, 34, 9854-9868. [CrossRef]

8. Yong-Hing, K.; Reilly, J.; Kirkaldy-Willis, W.H. The ligamentum flavum. Spine 1976, 1, 226-234. [CrossRef]

9. Yayama, T.; Baba, H.; Furusawa, N.; Kobayashi, S.; Uchida, K.; Kokubo, Y.; Noriki, S.; Imamura, Y.; Fukuda, M. Pathogenesis of calcium crystal deposition in the ligamentum flavum correlates with lumbar spinal canal stenosis. Clin. Exp. Rheumatol. 2005, 23, 637-643. [PubMed]

10. Schräder, P.K.; Grob, D.; Rahn, B.A.; Cordey, J.; Dvorak, J. Histology of the ligamentum flavum in patients with degenerative lumbar spinal stenosis. Eur. Spine J. 1999, 8, 323-328. [CrossRef] [PubMed]

11. Yoshida, M.; Shima, K.; Taniguchi, Y.; Tamaki, T.; Tanaka, T. Hypertrophied ligamentum flavum in lumbar spinal canal stenosis. Pathogenesis and morphologic and immunohistochemical observation. Spine 1992, 17, 1353-1360. [CrossRef]

12. Zhong, Z.M.; Zha, D.S.; Xiao, W.D.; Wu, S.H.; Wu, Q.; Zhang, Y.; Liu, F.Q.; Chen, J.T. Hypertrophy of ligamentum flavum in lumbar spine stenosis associated with the increased expression of connective tissue growth factor. J. Orthop. Res. 2011, 29, 1592-1597. [CrossRef]

13. Okuda, T.; Baba, I.; Fujimoto, Y.; Tanaka, N.; Sumida, T.; Manabe, H.; Hayashi, Y.; Ochi, M. The pathology of ligamentum flavum in degenerative lumbar disease. Spine 2004, 29, 1689-1697. [CrossRef]

14. Hur, J.W.; Kim, B.J.; Park, J.H.; Kim, J.H.; Park, Y.K.; Kwon, T.H.; Moon, H.J. The mechanism of ligamentum flavum hypertrophy: Introducing angiogenesis as a critical link that couples mechanical stress and hypertrophy. Neurosurgery 2015, 77, $274-282$. [CrossRef] [PubMed]

15. L€ohr, M.; Hampl, A.J.; Lee, J.Y.; Ernestus, R.I.; Deckert, M.; Stenzel, W. Hypertrophy of the lumbar ligamentum flavum is associated with inflamation-related TGF-beta expression. Acta Neurochir. 2011, 153, 134-141. [CrossRef] [PubMed]

16. Tkaczuk, H. Tensile properties of human lumbar longitudinal ligaments. Acta Orthop. Scand. 1968, 39 (Suppl. 115), 1-69. [CrossRef] [PubMed]

17. Jezek, J.; Sepitka, J.; Daniel, M.; Kujal, P.; Blankova, A.; Waldauf, P.; Krbec, M.; Dousa, P.; Skala-Rosenbaum, J.; Samal, F.; et al. The role of vascularization on changes in ligamentum flavum mechanical properties and development of hypertrophy in patients with lumbar spinal stenosis. Spine J. 2020, 20, 1125-1133. [CrossRef] [PubMed]

18. Chuang, H.C.; Tsai, K.L.; Tsai, K.J.; Tu, T.Y.; Shyong, Y.J.; Jou, I.M.; Hsu, C.C.; Shih, S.S.; Liu, Y.F.; Lin, C.L. Oxidative stress mediates age-related hypertrophy of ligamentum flavum by inducing inflammation, fibrosis, and apoptosis through activating Akt and MAPK pathways. Aging 2020, 12, 24168-24183. [CrossRef]

19. Abbas, J.; Hamoud, K.; Masharawi, Y.M.; May, H.; Hay, O.; Medlej, B.; Peled, N.; Hershkovitz, I. Ligamentum flavum thickness in normal and stenotic lumbar spines. Spine 2010, 35, 1225-1230. [CrossRef]

20. Safak, A.A.; Is, M.; Sevinc, O.; Barut, C.; Eryoruk, N.; Erdogmus, B.; Dosoglu, M. The thickness of the ligamentum flavum in relation to age and gender. Clin. Anat. 2010, 23, 79-83. [CrossRef] [PubMed]

21. Kim, Y.U.; Park, J.Y.; Kim, D.H.; Karm, M.H.; Lee, J.Y.; Yoo, J.I.; Chon, S.W.; Suh, J.H. The Role of the Ligamentum Flavum Area as a Morphological Parameter of Lumbar Central Spinal Stenosis. Pain Physician 2017, 20, E419-E424. 
22. Sairyo, K.; Biyani, A.; Goel, V.; Leaman, D.; Booth, R., Jr.; Thomas, J.; Gehling, D.; Vishnubhotla, L.; Long, R.; Ebraheim, N. Pathomechanism of ligamentum flavum hypertrophy: A multidisciplinary investigation based on clinical, biomechanical, histologic, and biologic assessments. Spine 2005, 30, 2649-2656. [CrossRef]

23. Myklebust, J.B.; Pintar, F.; Yoganandan, N.; Cusick, J.F.; Maiman, D.; Myers, T.J.; Sances, A., Jr. Tensile strength of spinal ligaments. Spine 1988, 13, 526-531. [CrossRef] [PubMed]

24. Pintar, F.A.; Yoganandan, N.; Myers, T.; Elhagediab, A.; Sances, A., Jr. Biomechanical properties of human lumbar spine ligaments. J. Biomech. 1992, 25, 1351-1356. [CrossRef]

25. Chazal, J.; Tanguy, A.; Bourges, M.; Gaurel, G.; Escande, G.; Guillot, M.; Vanneuville, G. Biomechanical properties of spinal ligaments and a histological study of the supraspinal ligament in traction. J. Biomech. 1985, 18, 167-176. [CrossRef]

26. Dumas, G.A.; Beaudoin, L.; Drouin, G. In situ mechanical behavior of posterior spinal ligaments in the lumbar region. An in vitro study. J. Biomech. 1987, 20, 301-310. [CrossRef]

27. Nishida, N.; Kanchiku, T.; Kato, Y.; Imajo, Y.; Suzuki, H.; Yoshida, Y.; Ohgi, J.; Chen, X.; Taguchi, T. Cervical ossification of the posterior longitudinal ligament: Factors affecting the effect of posterior decompression. J. Spinal Cord Med. 2017, 40, 93-99. [CrossRef]

28. Okazaki, T.; Kanchiku, T.; Nishida, N.; Ichihara, K.; Sakuramoto, I.; Ohgi, J.; Funaba, M.; Imajo, Y.; Suzuki, H.; Chen, X.; et al. Age-related changes of the spinal cord: A biomechanical study. Exp. Ther. Med. 2018, 15, 2824-2829. [CrossRef] 